\title{
Agricultural Service Center Location Problem: Concept and a MCDM Solution Approach
}

\author{
Morteza Zangeneh ${ }^{1}$, Peter Nielsen ${ }^{2}$, Asadolah Akram ${ }^{1}$, and Alireza Keyhani ${ }^{1}$ \\ ${ }^{1}$ Tehran University, Karaj, Iran \\ \{mzangeeh, aakram, akeyhani\} @ut.ac.ir \\ ${ }^{2}$ Aalborg University, Aalborg, Denmark \\ peter@m-tech.aau.dk
}

\begin{abstract}
The main aim of this study is to develop a multi-criteria decision making approach considering all aspects of the agricultural service center location problem (ASCLP). Initially a Delphi Fuzzy-AHP survey has been completed to extract the objectives and attributes of the ASCLP and their local weights. The main novel contribution of this paper is extracting and considering in a comprehensive manner the attributes and objectives for solving the problem of identifying: technical potential of candidate locations and demand and market location. By using the developed attributes, two scores (maxi-min and maximax) are computed for each candidate location and non-dominated solutions identified.
\end{abstract}

Keywords: Attribute, Objective, Service, Location, Agriculture.

\section{Introduction}

\subsection{Agricultural Services}

Agriculture is the only major sector that uses the land surface as an essential input into its production function. This wide geographical dispersion of agricultural production has the important economic consequence; transportation becomes essential. Output must be transported for consumption by others and inputs; such as modern seeds, fertilizer, pesticides, or machinery, must be transported to the farm to raise output (Timmer, Falcon et al. 1983). Locating and sizing facilities to serve customers is an aspect of supply chain design that presents a number of challenges. Customers are sensitive to the total cost of interacting with a firm's service, including time and access costs, in addition to price (Pangburn and Stavrulaki 2005). Several services can be provided to the whole agricultural supply chain $(\mathrm{ASCH})$ includes: Input supply, mechanization, advisory, financial, inspection, business and etc. Unfortunately, the majority of supplier companies remains concentrated in urban areas or rural zones with large concentrations of commercial farmers. Therefore millions of poor farmers in rural areas without large commercial farmers do not have access to affordable agricultural inputs such as improved seeds, chemical fertilizers and other agro chemicals 
needed to raise farm productivity (Dorward and Chirwa 2011). The manufacture, distribution, repair, maintenance, management and utilization of agricultural tools, implements and machines are covered under the discipline of mechanization services (Lak and Almasi 2011). The basic indicators for the success of a demand-driven advisory service system in agriculture are: farmers have access to and use agricultural advisory services (Chipeta 2006).

\subsection{Agricultural Service Center Location Problem}

Location problems (LP) in agriculture exhibit several features, such as their large scope and size, or the consideration of multiple and often conflicting objectives and, thus, implies high levels of complexity (Lucas and Chhajed 2004). Agricultural services have different characteristics than other public services such as health, police or etc., resulting in somehow different location selection procedure. The details of the current LP are shown in Table 1. There are three types of customers in this LP: Customer type A; The number of farms is very large. Any demand point has different types of service requirements. Any demand point may need several services at any given time. Candidate locations and demand points are the same (both are village points). For transport of any product it is enough to reach the demand point and the specific destination is not important in this LP.

Customers type B and C; they want access to the services at their location. This type may be available or not in some rural regions.

Table 1. Services description

\begin{tabular}{|c|c|c|c|c|c|c|c|}
\hline \multirow[t]{3}{*}{ Characteristics } & \multicolumn{7}{|c|}{ Service type } \\
\hline & \multirow{2}{*}{\begin{tabular}{l}
\multicolumn{1}{c}{ Pre- } \\
Production \\
Input \\
supply
\end{tabular}} & \multicolumn{3}{|c|}{ Production } & \multicolumn{3}{|c|}{ Post Production } \\
\hline & & $\begin{array}{l}\text { Mechaniza- } \\
\text { tion }\end{array}$ & $\begin{array}{l}\text { Consulting } \\
\text { for farms }\end{array}$ & Financial & $\begin{array}{l}\text { Consult- } \\
\text { ing }\end{array}$ & Inspection & $\begin{array}{l}\text { Busi- } \\
\text { ness }\end{array}$ \\
\hline $\begin{array}{l}\text { Times for each } \\
\text { season }\end{array}$ & Single & Multiple & Multiple & Single & Multiple & Single & Multiple \\
\hline $\begin{array}{l}\text { Customer for } \\
\text { each service }\end{array}$ & A & A & A & A & $\mathrm{B}, \mathrm{C}$ & $\mathrm{B}, \mathrm{C}$ & $\mathrm{A}, \mathrm{B}, \mathrm{C}$ \\
\hline $\begin{array}{l}\text { Location of } \\
\text { service demand }\end{array}$ & On farm & On farm & $\begin{array}{l}\text { On service } \\
\text { center }\end{array}$ & $\begin{array}{l}\text { On } \\
\text { service } \\
\text { center }\end{array}$ & On site & On site & On site \\
\hline Capacity & Unlimited & Limited & Unlimited & Limited & Unlimited & Unlimited & Limited \\
\hline $\begin{array}{l}\text { Demand } \\
\text { weight }\end{array}$ & Weighted & Weighted & $\begin{array}{l}\text { Un- } \\
\text { weighted }\end{array}$ & Weighted & $\begin{array}{l}\text { Un- } \\
\text { weighted }\end{array}$ & $\begin{array}{l}\text { Un- } \\
\text { weighted }\end{array}$ & $\begin{array}{l}\text { Weighte } \\
\text { d }\end{array}$ \\
\hline Time criticality & Yes & Yes & No & Yes & No & No & Yes \\
\hline
\end{tabular}


The layout of the agricultural service center location problem (ASCLP) is shown in Fig. 1. Since there are several services, so more distance functions should be considered.

Fig. 1. Layout of the agricultural service network

In this paper, initially a Delphi Fuzzy Analytic Hierarchy Process (Delphi-FAHP) survey has been completed to extract the objectives and attributes of ASCLP. After that, using FAHP the local weight of location attributes for the LP has been computed. In this paper a stepwise approach to solve the ASCLP has been introduced. So the main aim of this study is to develop a multi-attribute decision making approach considering all aspects of this LP. The ideal solution for this problem should satisfy the main objectives, including simultaneously: maximizing service quality, service speed, and service centers profit and minimizing service cost. Widespread demand and the short available time to respond to them is the main distinguishing feature of current LP in compare to classical production systems.

\section{$2 \quad$ Material and Methods}

Generally in this research, the FAHP has been used to assess the location indicators (both objectives and attributes) of agricultural service centers (ASC) (Cho and Lee 2013). Using the FAHP method, the ASC location attributes has been prioritized based on objectives which have no differences. Another phase is however added to the framework to address the possible differences between objectives using Multi Choice Goal Programming, i.e. in the case that the priority of objectives is not the same. So this research has five main phases for assessing the location attributes (see Fig. 2). To select the best candidate location for ASC, some sub-attribute for each location attribute which can easily be measured has been defined (see Table 2). 
Table 2. The attribute and sub-attribute for ASCLP

\begin{tabular}{|c|c|c|}
\hline Attribute & \multicolumn{2}{|c|}{ Sub-attribute } \\
\hline Easy support: $\chi_{1}$ & $\begin{array}{c}\text { Distance to center of county } \\
\text { (maxi-min): } C_{11}\end{array}$ & $\begin{array}{c}\text { Distance to center of district } \\
\text { (maxi-min): } C_{12}\end{array}$ \\
\hline $\begin{array}{c}\text { Proximity to more population } \\
\text { and cultivated lands: } \chi_{2}\end{array}$ & $\begin{array}{c}\text { The number of families (maxi- } \\
\text { max): } C_{21}\end{array}$ & $\begin{array}{c}\text { Total cultivated area } \\
\text { max): } C_{22}\end{array}$ \\
\hline Easy access: $\chi_{3}$ & Total distance to other villages (maxi-min): $C_{31}$ \\
\hline $\begin{array}{c}\text { Proximity to less tractor and ma- } \\
\text { chinery availability: } \chi_{4}\end{array}$ & $\begin{array}{c}\text { Number of tractors (maxi-min): } \\
C_{41}\end{array}$ & $\begin{array}{c}\text { The value of mechanization effi- } \\
\text { ciency (maxi-min): } C_{42}\end{array}$ \\
\hline $\begin{array}{c}\text { Proximity to more service de- } \\
\text { mand: } \chi_{5}\end{array}$ & $\begin{array}{c}\text { The number of crop type culti- } \\
\text { vated (maxi-max): } C_{51}\end{array}$ & $\begin{array}{c}\text { The ratio of irrigated cultivated } \\
\text { land to dried cultivated land (maxi- } \\
\text { max): } C_{52}\end{array}$ \\
\hline
\end{tabular}

Fig. 2. Summary of proposed MCDM approach

The Eq. 1 can be used to calculate the value of each attribute for each candidate location: 


$$
\chi_{i j}=\sum_{k=1}^{p} \tilde{C}_{k} \quad \forall i, j
$$

Where; $k$ is the index of sub-attribute and $\tilde{C}_{k}$ is the normalized value of subattribute $k$.

Since the unit of sub-attributes is different, to use them in formulations, they are converted to a normal range between one and zero before calculation of decision parameters using Eq. (2):

$$
\tilde{C}_{k}=\frac{C_{k}-\min C_{k}}{\max C_{k}-\min C_{k}} \forall i, j
$$

There are two type of attributes viewpoint of their preferred values, for example lower values of distances (e.g. $\chi_{1}$ ) are preferred, while higher values of total cultivated area is outranked to select such a candidate location for establishing an ASC. So, two separate formulations for maxi-min and maxi-max attributes (see Eq. 3 and 4) are defined. These equations will be used to compute the suitability of candidate locations for service center establishment.

$$
\begin{aligned}
S_{i}^{\nabla} & =\sum_{i=1}^{n} \gamma_{j}\left[\chi_{i j}\right] \quad(j=1,3,4) \\
S_{i}^{\Delta} & =\sum_{i=1}^{n} \gamma_{j}\left[\chi_{i j}\right] \quad(j=2,5)
\end{aligned}
$$

Where; $i$ is the index of candidate locations and demand points, $j$ is the index of attributes of ASCLP, $S_{i}^{\nabla}$ is the final score of candidate location $i$ for attributes where lower values of them are preferred (maxi-min), $S_{i}^{\Delta}$ is the final score of candidate location $i$ for attributes where greater values of them are preferred (maxi-max), $\gamma_{j}$ is the importance weight of attribute $j$ obtained from FAHP and $\chi_{i j}$ is the value of attribute $j$ for candidate location $i$.

After calculating the final scores of each candidate location, they will be ranked based on their score values. Then candidate locations which their score of maxi-min $\left(S_{i}^{\nabla}\right)$ is lower than a threshold ( $\alpha \%$ of the selected range which identified by decision maker) and also for maxi-max scores $\left(S_{i}^{\Delta}\right)$ which is higher than a threshold ( $\beta \%$ of the selected range which identified by decision maker) will be selected and categorized in two set of $A_{\rho}$ and $B_{\rho}$ for each region of study (see Eq. 5 and 6).

$$
\begin{aligned}
A_{\rho} & =\left\{i \mid S_{i}^{\nabla} \leq \alpha \% \text { of the selected range }\right\} \\
B_{\rho} & =\left\{i \mid S_{i}^{\Delta} \geq \beta \% \text { of the selected range }\right\}
\end{aligned}
$$

In the last step of this approach, locations are selected which satisfy both selection conditions described previously. The aim of this study is to select at least one location for each region to open a service center, locations will be selected which is in the subset of $A_{\rho}$ and $B_{\rho}$ (see Eq. 7):

$$
Y_{\rho}=A_{\rho} \cap B_{\rho}
$$


Where; $\rho$ is the index of region $\rho=(1, \ldots, 7), A_{\rho}$ is the set of candidate locations selected by using the minimization selection criteria, $B_{\rho}$ is the set of candidate locations selected by using the maximization selection criteria, $Y_{\rho}$ is the final selected locations for region $\rho$.

After finding the set of $Y_{\rho}$, one must propose the best location, because potentially more than one location satisfies the selection conditions. In classic location models the distance function is always used to select the best location. However in this case due to the characteristics of agricultural services, other attributes (technical aspects of the locations) supplementing the distance function should be imported.

\section{Results and Discussion}

The approach proposed in this paper can quickly lead to the best non-dominated solution, as it utilizes simple calculations and uses measurable attributes. To prove the capability of proposed approach, a case study of Iran has been done.

Using the defined set conditions, candidate location which satisfied the selection condition in each region has been selected and the numbers of selected candidate locations are illustrated in Table 3.

Table 3. The set of selected locations in each region

\begin{tabular}{|l|l|l|l|}
\hline Region & \multicolumn{1}{|c|}{$A_{\rho}$} & \multicolumn{1}{c|}{$B_{\rho}$} & $Y_{\rho}$ \\
\hline Boqrati & $\{1,3,4,7,8,12\}$ & $\{4,5,7,11,12,13\}$ & $\{4,7,12\}$ \\
\hline Darjazin-Olia & $\{2,3,4,6,7,8,10,12,13,14,15$ & $\{3,4,6,8,9,10,14,15\}$ & $\{3,4,6,8,10,1$ \\
& & & $4,15\}$ \\
\hline Darjazin-Sofla & $\{2,3,4,5,6,9,10\}$ & $\{1,5,6,9,10,12,14\}$ & $\{5,6,10\}$ \\
\hline Kharaqan & $\{2,3,4,5,6,8,10\}$ & $\{2,7,8,9,11,12,15\}$ & $\{2,8\}$ \\
\hline Razan & $\{2,3,4,5,7,8,9,10,14,17\}$ & $\{1,5,6,7,10,13,15,17,20,21\}$ & $\{5,7,10,17\}$ \\
\hline Sardrood-Olia & $\{1,2,3,6,7\}$ & $\{2,4,6,9,11\}$ & $\{2,6\}$ \\
\hline Sardrood-Sofla & $\{2,3,5,6,7,8,10\}$ & $\{1,2,4,5,6,13,14\}$ & $\{2,5,6\}$ \\
\hline
\end{tabular}

$\alpha=50 \%, \beta=50 \%$

Usually in location decisions, distance and transportation play a very important role. So in this paper the role of maxi-min attributes is highlighted, which contains different distance functions, in selecting the best solutions. As can be seen in fig.3, in Boqrati regions, one of studied regions, there is no unique non-dominated solution. In Boqrati region, $S_{4}^{\nabla}$ is lower than $S_{7}^{\nabla}$ while $S_{7}^{\Delta}$ is higher than $S_{4}^{\Delta}$. In this situation no one can dominate the other one. In such cases the decision maker has to propose all non-dominated solutions and this is the main disadvantage of proposed approach, while it has several advantages such as simplicity of calculations, the ability to consider inherent specification of agricultural activities. 


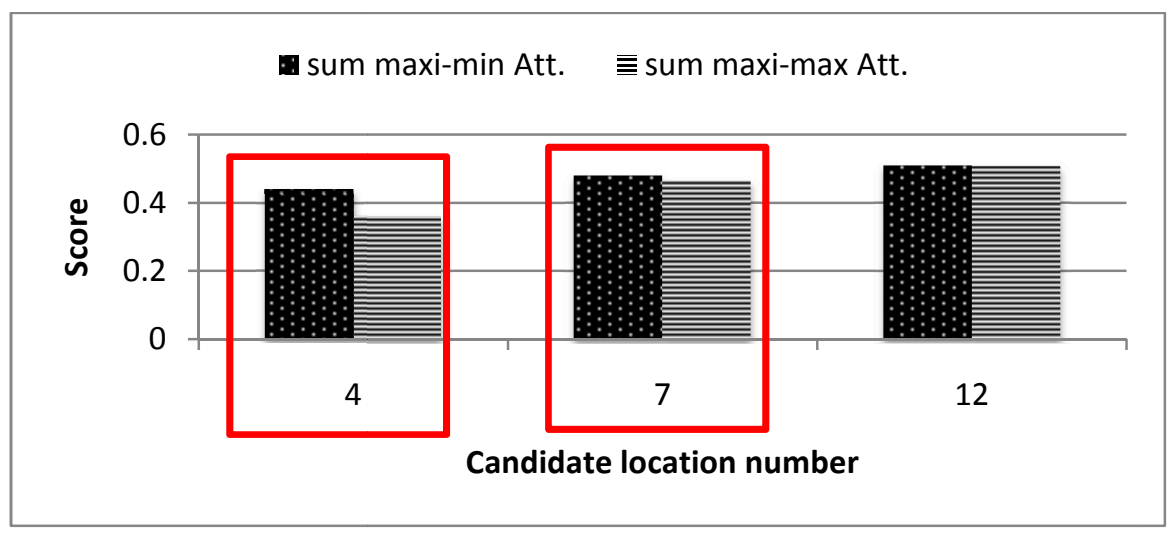

Fig. 3. The chart of selected locations of Boqrati

\section{Conclusion}

In this paper a concept is presented and a fast and intelligible approach to solve an important agricultural facility location problem is developed. Agricultural services due to their dispersed customers' need to be optimally distributed and be able to supply all required services. The ASCLP also plays an important role in the efficiency of the ASCH. As can be understood from the results of this research, establishing an ASC network can lead to high quality services, low price and cost, fast deliver services, and sustainable service centers able continue their activity due to good estimated customer availability for their services. In this paper all aspects of the ASCLP have been considered, i.e. from the viewpoint of customers and service suppliers, and also technical suitability of candidate location for locating the service center on them.

\section{References}

1. Chipeta, S.: Demand driven agricultural advisory services. Neuchatel Group, Denmark (2006)

2. Cho, J., Lee, J.: Development of a new technology product evaluation model for assessing commercialization opportunities using Delphi method and fuzzy AHP approach. Expert Systems with Applications 40, 5314-5330 (2013)

3. Dorward, A., Chirwa, E.: The Malawi agricultural input subsidy programme: 2005/06 to 2008/09. International Journal of Agricultural Sustainability 9(1), 232-247 (2011)

4. Lak, M.B., Almasi, M.: An analytical review of parameters and indices affecting decision making in agricultural mechanization. Australia Journal of Agricultural Engineering 2(5), $140-146(2011)$

5. Lucas, M., Chhajed, D.: Applications of location analysis in agriculture: a survey. Journal of the Operational Research Society 55(6), 561-578 (2004)

6. Pangburn, M.S., Stavrulaki, E.: Service Facility Location and Design with Pricing and Waiting-Time Considerations. Supply Chain Optimization 98, 209-241 (2005)

7. Timmer, C.P., et al.: Food policy analysis. The Johns Hopkins University Press, Baltimore (1983) 